REVISTA DE DERECHO UNED, NÚM. 10, 2012

\title{
LOS PUEBLOS ORIGINARIO AMERICANOS EN LA FORMACIÓN DE LOS ESTADOS HISPANOAMERICANOS
}

\author{
CAYETANo NúÑEz Rivero \\ UNED
}

Resumen: En el trabajo se lleva a cabo un análisis histórico del tratamiento legal de los pueblos originarios americanos desde la conformación de formas estatales, comenzando en el periodo dominante de la Corona española, continuando con el constitucionalismo de los primeros Estados de Derecho y finalizando con la emergencia del Estado Plurinacional; a este respecto, se analizan los conceptos de segregación, asimilación, integración y pluralismo nacional.

Abstract: In the work an historical analysis of the legal treatment of the American original towns is carried out from the conformation of state forms, beginning in the dominant period of Spanish Corona, continuing with the constitution of the first States of Right and finalizing with the emergency of the multiinational State; in this respect, the concepts of segregation, assimilation are analyzed, integration and national pluralism.

Palabras Clave: Antiguo Régimen, Corona, Estado de Derecho, Estado Plurinacional, Comunidades originarias, asimilación, integración.

Key words: Old Regime, Crown, State of Right, multinational State, original Communities, assimilation, integration.

Sumario: 1. Introducción.-2. Los pueblos originarios de América en la legislación española.-3. Tratamiento del tema en el primer constitucionalismo hispanoamericano: 3.1. En los primeros textos españoles. 3.2. Los primeros textos constitucionales americanos y la

(C) UNED. Revista de Derecho UNED, núm. 10, 2012 
población indígena.- 4. El Estado Plurinacional latinoamericano en la actualidad.

\section{INTRODUCCIÓN}

Respecto a los pueblos originarios de América, desde el origen de la existencia de formas estatales en el territorio, es decir, desde el momento que podemos hablar del ejercicio del poder en una comunidad políticamente organizada ${ }^{1}$, hasta el presente, podemos distinguir las siguientes políticas de integración seguidas en las entidades nacionales ${ }^{2}$ :

a) Segregación.

b) Asimilación.

c) Intentos de integración.

d) Reconocimiento del pluralismo nacional, lo que implica refundación del concepto Nación-Estado.

El primer punto corresponde al periodo colonial, el segundo se refiere a los primeros tiempos de los nuevos Estados hispanoamericanos, el tercero se produce a mediados del siglo XX y el último corresponde a la época actual.

No obstante lo indicado, debe tenerse en cuenta, que la frontera entre los diferentes modelos, no siempre es de carácter diáfano, produciéndose matices, que si no alteran el aspecto conceptual, sí modifican parcialmente el desarrollo de los mismos, especialmente en lo referente al primero y segundo apartado, aunque sólo sea por el largo periodo de tiempo en que estuvieron vigentes.

Por otra parte, hay algunos aspectos que consideramos fundamentales para la comprensión y aceptación del modelo propuesto; en primer lugar, debe considerarse, que cuando nos referimos al periodo de segregación existente en la América Española, éste es de un carácter radicalmente diferente al existente en las posesiones inglesas en el

${ }^{1}$ En la opinión que sostenemos, la emergencia de formas estatales en el continente americano, en cuanto cuentan con una población estable y permanente, un territorio determinado y una estructura institucional y normativa, se produce a partir del siglo XVI; véase al respecto, NÚÑEZ RIVERO, Cayetano; NÚÑEZ MARTINEZ, María, (2009) «El bicentenario. ¿Doscientos años de de Estado o solamente dos siglos de República?» Revista de Derecho n ${ }^{\circ}$ 5. UNED. Madrid...

2 Véase al respecto, CABEDO MALLOL, Vicente (2004), «Constitucionalismo y Derecho Indígena en América Latina»; Univ. Politec. Valencia, págs. 83 y ss. 
Nuevo Mundo, de tal forma, que constituye un modelo exclusivo al respecto, como veremos en epígrafe posterior.

Igualmente, es de gran importancia, que tengamos en cuenta, que cada uno de los modelos indicados se produce en momentos históricos radicalmente diferentes, donde los principios y valores de la sociedad son dispares, y no sólo en el aspecto indicado, sino en el conjunto de la estructura económica, social y política del Estado.

Valga a este respecto una primera diferenciación fundamental, correspondiente al paso del periodo de segregación al de asimilación, pues si el primero acontece en unas estructuras propias del Antiguo Régimen, el segundo y posteriores tienen su desarrollo en la estructura del Estado de Derecho; de tal forma, que la concepción del elemento humano conformador del concepto Nación es radicalmente diferente, pues si en el Antiguo Régimen, el ser humano perteneciente a un determinado Reino, es considerado como súbdito del Rey, independientemente del estamento al que pertenezca en la estructura social, en los estadios correspondientes al Estado de Derecho, una vez desaparecida la estructura estamental, alcanza la categoría de ciudadano del Estado, independientemente de la clase social en la que se ubique, portador por tanto de una serie de derechos y libertades individuales, totalmente alejados del concepto de vasallaje imperante en el periodo anterior. Así mismo, aunque no de un carácter tan radical como el indicado, podemos percibir grandes diferencias de carácter general entre las diferentes conformaciones del Estado de Derecho en lo que respecta a la ciudadanía, así, si nos remontamos al primer Estado Liberal, encontramos una ciudadanía restringida, o unos derechos recortados de esta ciudadanía, en cuanto el principio de soberanía nacional queda desvirtuado por la proclamación del sufragio censitario, a diferencia del Estado Liberal Democrático, y más aún del Estado Social y Democrático de Derecho, donde tras la plena proclamación de la Soberanía Popular, se establece el sufragio universal masculino y femenino, alcanzándose en el último caso otras formas de participación ciudadana, tales como la democracia representativa.

\section{LOS PUEBLOS ORIGINARIOS DE AMÉRICA EN LA LEGISLACIÓN ESPAÑOLA}

Sobre este punto, hay que partir de un hecho que consideramos trascendental y que va a marcar la política española al respecto, como es la importancia de la religión católica en la conformación de la Nación española y del propio Imperio español. 
En primer lugar, debemos destacar que no es posible encontrar en el origen de Estado Moderno alguno una unión tan grande entre la religión y la Corona como en el nacimiento y conformación de la Monarquía renacentista española. A este respecto, la explicación es obvia, el poder político, en el proceso de creación de las Monarquías Autoritarias, tratando de imponerse a los diversos poderes locales, precisaban de elementos aglutinantes que coadyuvaran a la conformación de un sentimiento nacional. En este sentido, cuando se produce el acceso al trono de los Reyes Católicos en Castilla y Aragón, en su deseo de crear una unidad nacional española en las postrimerías del siglo XV, no se cuenta con el aglutinante lingüístico, como en la Francia contemporánea, ya que España no contaba con un idioma único, pues cada Reino tenía una lengua diferente, así como varios dialectos, y de hecho, hasta principios del siglo XVIII, con la llegada del centralismo borbónico no se impuso el castellano como lengua oficial del Estado. Tampoco podían establecerse razones de carácter étnico, como fue el caso de Alemania en el momento de conformar su unidad nacional mediante el concepto del pangermanismo, pues no existía raza predominante alguna, aunque sí un considerable mestizaje. Respecto a una cultura y creencias comunes, tampoco era muy perceptible, en virtud fundamentalmente de la división entre la España cristiana y la musulmana imperante durante ocho siglos, existía quizás en este aspecto un cierto recuerdo de pasado común remontándose a la España visigótica de mil años atrás, que por otra parte no abarcaba tampoco a la totalidad del territorio peninsular. Aunque la religión cristiana no era tampoco única en el territorio, sí era el elemento aglutinante de la mayoría de la población, en cuanto que los que no la profesaban eran o una minoría, que presentaba aspectos marginales, caso de la hebraica, o los habitantes de un reino vencido, caso de los granadinos.

Es pues, en este contexto en el que el poder político se apoyará en la religión como elemento unificador, de donde se deriva la importancia que la religión jugará posteriormente en el Estado ${ }^{3}$.

La transformación de la Monarquía española en Imperio acentuó más si cabe la importancia de la religión como aglutinante del Estado, ya que el acceso del Rey Carlos I a la Corona imperial con el título de Carlos V suponía la herencia del viejo Imperio Sacro Romano Germánico, que tenía su justificación en la representación del poder Temporal de Dios como Vicario en la tierra, teoría que sería especialmente defendida por los teólogos españoles de la época. El concepto

3 Cayetano NÚÑEZ RIVERO (2002), «Derecho Constitucional Comparado y Derecho Político iberoamericano», Ed. Universitas-UNED, Madrid, pág. 30 y ss. 
de Monarquía Múltiple que se desarrollará durante el reinado de Carlos I, Felipe II y los restantes Habsburgos implicará la unión no sólo por la figura del Monarca, sino por la religión compartida, aspecto que se incrementará, una vez que se desgajen de esta forma de Monarquía Universal los territorios centroeuropeos que pasarán tras la abdicación de Carlos V a la rama de los Habsburgo austriacos y que es donde precisamente se habían producido los brotes del movimiento protestante. De esta forma, la totalidad de los territorios sujetos al concepto de imperio español, con la excepción de los Países Bajos, donde se producirán interminables guerras de religión, que en el fondo disfrazarán luchas por la independencia y por la incipiente revolución burguesa holandesa, estarán sujetos a la Religión Católica, y será objetivo primordial del trono su defensa, sea en el Mediterráneo contra la expansión turca, como en el continente europeo e Inglaterra contra la «herejía» protestante, pero siempre en defensa del Papado.

En este contexto descrito se inicia la conquista y colonización de las nuevas tierras americanas. Cabe destacar que desde las primeras expediciones de descubrimiento y asentamiento en los nuevos territorios se pone de manifiesto el interés por parte de la Corona de llevar a los nativos de aquellas tierras el conocimiento de la Religión Católica:

"que sus ánimas no se pierdan, para lo cual es menester que sean informados de las cosas de nuestra santa fe católica.» ${ }^{4}$

Las razones de la Corona para la expansión de la religión a las Indias, es consecuencia en principio, de la doctrina de la teocracia ${ }^{5}$, desarrollada en el Medioevo a favor de la universal soberanía papal, que legitimaba la adquisición de nuevos territorios para los monarcas cristianos, en virtud de que ello significara la incorporación al seno de la Iglesia de estos pueblos, de tal forma, que «el descubrimiento y ocupación por un príncipe cristiano de tierras habitadas por infieles con ánimo de convertirlos a la fe católica constituía un título legítimo suficiente de adquisición de las mismas, según el derecho de la época» ${ }^{6}$, de tal forma, que sobre los Príncipes cristianos convertidos en soberanos pesaba el deber de misionar y de establecer allí el conjunto de ordenaciones precisas para hacer posible la vida religiosa de un pueblo cristiano $^{7}$, así mismo, podemos entender que

${ }^{4}$ Real cédula de 1509.

5 P. CASTAÑEDA, La Teocracia pontifical y la conquista de América (1968), Vitoria.

6 GARCÍA GALLO, Las Bulas alejandrinas (1987), Madrid, págs. 661-662.

7 Véase Alberto DE LA HERA; C. SOLER (1994), «Historia de las doctrinas sobre las relaciones entre la Iglesia y el Estado», en VVAA, Tratado de Derecho Eclesiástico, Pamplona, págs. 35-84. 
tal actitud de la Corona se deriva del propio sentimiento religioso de los monarcas, así como del interés de conformar una sociedad en aquellas tierras similar a la existente en la península, regida por las mismas normas y costumbres; a tal efecto, podemos indicar los controles impuestos para la emigración de la población europea al Nuevo Mundo, controlada por la Casa de la Contratación ${ }^{8}$, a la que se sumaría pronto la Inquisición ${ }^{9}$ que a principios del siglo XVI comenzaría sus actividades en las Indias ${ }^{10}$. Estos controles impedían la emigración a las Indias de toda persona que no profesara la Religión Católica Apostólica Romana, impidiendo incluso el acceso de conversos castellanos.

De lo indicado anteriormente, se desprende que el elemento de identidad de la nacionalidad española era la religión católica, y a tal efecto, las autoridades de la Corona pondrán todo su empeño en esta tarea respecto a la conversión de los pueblos originarios americanos. «(...) Y para que todos universalmente gocen el admirable beneficio de la Redención por la Sangre de Christo nuestro Señor, rogamos, y encargamos á los naturales de nuestras Indias, que no hubiesen recibido la Santa Fe, pues nuestro fin es en prevenirles y enviarles $M a$ estros y Predicadores, es el provecho de su conversión y salvación, que los reciban y den entero crédito á su doctrina... ${ }^{11}$, debiendo destacarse, que a tal efecto, la conversión del originario americano, suponía el acceso al principio de igualdad con los demás súbditos del Rey, como proclama la segunda ley de la citada Recopilación ${ }^{12}$ "(...) que en llegando á aquellas Provincias procurasen luego dar á entender, por medio de los intérpretes, á los Indios y moradores, ...buenas costumbres, apartarlos de vicios y comer carne humana, instruirlos en la Santa Fe Católica y predicársela para su salvación, y atraerlos á nuestro Señorío,

${ }^{8}$ La Casa de la Contratación se conformó mediante Real Cédula de 1503, teniendo como objetivo fundamental en su origen el control de comercio con las Indias, en lo referente a importación y exportación, posteriormente, en virtud del auge de dicho comercio y de la emigración a las Indias se incrementarían sus atribuciones, incorporando algunas de carácter judicial «ley XVI, Título I, Libro IX de la Recopilación de Indias», "Real Provisión de 26 de septiembre de 1511».

${ }_{9}$ Los primeros Comisarios del Santo Oficio en tierras americanas fueron el Obispo Manso en Puerto Rico y el dominico Pedro de Córdoba en la isla Española; posteriormente se trasplantaría a Nueva España (1535) y Perú (1539); no obstante, desde 1517 todos los Obispos de las Indias tenían poderes inquisitoriales.

${ }^{10}$ La cédula fundacional del Tribunal de la Inquisición data de 1569; el primer Tribunal se estableció en Lima en 1570, posteriormente lo hizo el de México en 1571, siendo el tercero el de Cartagena de Indias en 1610.

11 Recopilación de las Leyes de los Reynos de Indias; Ley I, Libro I, Título I.

12 Otorgada por Carlos I a 17 de noviembre de 1526. 
porque fuesen tratados, favorecidos y defendidos como los otros nuestros súbditos y vasallos...» ${ }^{13}$

De lo anteriormente indicado, podemos sacar la conclusión, de que la política segregacionista española, tenía un alto contenido de política asimilacionista, en cuanto que el acceso a la religión católica permitía el acceso a la condición de súbdito real en condiciones similares a los otros habitantes del territorio provenientes en este caso de España, lo que no impedía la eliminación de las grandes diferencias de situación, económica y social imperantes, propias de una sociedad estamental, como era la del Antiguo Régimen.

No obstante, mantenemos el término segregacionista, en cuanto que la política real no era directamente la de integración de las comunidades indígenas en la estructura social española, de tal forma, que las ciudades americanas se van a organizar según el patrón castellano y sujetas a la legislación imperante en el resto del Reino, lo que no impide que desde la Corona se impulse la urbanización de las comunidades originarias americanas, donde también se implantará la legislación castellana.

Sobre el tema indicado de segregación, término que en realidad debería ser sustituido por el de separación, podemos indicar, que al menos, en un cierto aspecto, éste debe ser considerado como resultado de un cierto ámbito protector de la Corona hacia este sector poblacional, amenazado por el choque brutal de ambas culturas y por la actuación de los primeros emigrantes españoles, guiados por el espíritu desmedido de obtención de riquezas; valga como ejemplo de esta afirmación, la Ley I del Libro Sexto, Título I «De los Indios» ${ }^{14}$, en la que el Rey Felipe II, a 24 de diciembre de 1580, proclama, «Habiendo de tratar en este libro la materia de Indios, su libertad, aumento, y alivio, como se contiene en los titulos de que se ha formado: Es nuestra voluntad encargar á los Virreyes, Presidentes y Audiencias el cuidado de mirar por ellos, y dar las órdenes convenientes, para que sean amparados, favorecidos y sobrellevados, por lo que deseamos, que se remedien los daños que padecen, y vivan sin molestia, ni vexación, quedando esto de una vez sentado, y teniendo muy presentes las leyes de esta Recopilación, que les favorecen, amparan y defienden de cualquier agravio, y que las guarden, y hagan guardar muy puntualmente, castigando con particular, y rigurosa demostración á los transgresores. Y ro-

${ }_{13}$ Cabe destacar la gran extensión legislativa dedicada directamente a la conversión de los indios, ya que todo el Título I del Libro I de las Leyes de Indias se dedica a este respecto.

14 Recopilación de las Leyes de los Reynos de Indias. 
gamos y encargamos á los Prelados Eclesiásticos, que por su parte lo procuren como verdaderos Padres espirituales de esta nueva Christiandad, y todos los conserven en sus privilegios, y prerrogativas, y tengan en su protección».

Cabe destacar, que en la citada Recopilación de indias se dedica todo el Libro VI al tema de los pueblos Originarios de las nuevas tie$\operatorname{rras}^{15}$, debiendo resaltarse, que el Título II, denominado «De la Libertad de los Indios», contiene proclamaciones que prohíben la esclavitud de los Indios en cualquier circunstancia, tanto a las autoridades del Estado, como a los particulares, ni por motivo de compra o conquista, incluso en el caso de que la detención del Indio fuera consecuencia de Guerra justa ${ }^{16}$, prohibiendo incluso, que pudiera existir tal condición, aunque tal estado de esclavitud ya existiera anteriormente por parte de otros naturales de la Región; así mismo, se prohíbe que los Caciques y Principales de los pueblos originarios puedan vender, trocar o poseer esclavos ${ }^{17}$, llegando incluso a proclamar, que los originarios de las tierras pertenecientes al Rey de Portugal, que accedieran a los territorios de la Corona española, sean liberados de tal condición ${ }^{18}$. Para el cumplimiento de estas Reales Órdenes, se instituyó la figura de un Ministro, apoyado por los Fiscales de las Audiencias, que conociera de la libertad de los Indios, "Nos deseando su libertad, ordenamos, que los Virreyes y Presidentes de todas las Reales Audiencias nombren un Ministro, ú otra persona de satisfacción, y buena conciencia, que visite, y conozca de estas causas en cada provincia, para que no siendo las esclavitudes permitidas por derecho, y por leyes de este libro, las dé por nulas, y ponga á los Indios en su libertad natural, sin embargo de qualquiera posesión» ${ }^{19}$.

El aspecto indicado anteriormente de la separación de la comunidad de Españoles y de Indios se deriva del interés de la Corona por el control de la población en el Nuevo Mundo, a este respecto ya hemos indicado la conformación de ciudades españolas a imagen y semejanza de las existentes en la península; respecto a la población autóctona, se mantiene la misma actitud, el objetivo en este caso es conformar grandes poblaciones de los mismos, con el fin de que los mismos sean instruidos en la Fe Católica, mejorando al mismo tiem-

${ }^{15}$ Se incluye también a los pueblos originarios de Filipinas.

${ }^{16}$ Ley I, Libro VI Título II.

17 Ley III, Libro VI Título II.

${ }_{18}$ Ley V, Libro VI Título II.

${ }^{19}$ Ley IX X, Libro VI Título II. 
po la situación económica de los mismos, "Con mucho cuidado y particular atención se ha procurado siempre interponer los medios mas convenientes para que los Indios sean instruidos en la Santa Fe Católica, y Ley Evangélica, y olvidando los errores de sus antiguos ritos, y ceremonias, vivan en concierto, y policía; y para que esto se executase con mejor acierto, se juntaron diversas veces los de nuestro Consejo de Indias, y otras personas Religiosas, y congregáron los Prelados de Nueva España el año 1546 por mandato de del Señor Emperador Carlos V... con deseo de acertar en servicio de Dios, y nuestro, resolvieron que los Indios fuesen reducidos á Pueblos, y no viviesen divididos, y separados por las sierras, y montes, privándose de todo beneficio espiritual, y temporal, sin socorro de nuestros Ministros, y del que obligan las necesidades humanas, que deben dar unos hombres á otros...»20; no obstante, debe resaltarse que en la ley de referencia, se manifiesta, que tal medida se lleve a cabo sin violencia alguna «...y por haberse reconocido la conveniencia de esta resolución por diferentes órdenes de los Señores Reyes nuestros predecesores, fue encargado, y mandado á los Vireyes, Presidentes, y Gobernadores, que con mucha templanza y moderación executasen la reducción, población, y doctrina de los Indios con tanta suavidad, y blandura, que sin causar inconvenientes, diese motivo á los que no se pudiese poblar luego, que viendo el buen tratamiento, y amparo de los ya reducidos, acudiesen á ofrecerse de su voluntad..."; "Los Vireyes, y Presidentes Gobernadores nombrarán Ministros, y personas de muy entera satisfacción para reducir los Indios á su origen, y población, procurando que se haga con tanto desinterés y suavidad, que no intervenga compulsión, ni otro género de apremio, con que el beneficio resulte en su daño, representando á los naturales su mismo bien, y conveniencia, y apercibiendo a los Corregidores, y Caciques interesados, que no usen de mal trato, ni pongan impedimento, y á los Seculares, que hallaren culpados castiguen severa y exemplarmente; y si fueran Eclesiásticos, lo hagan saber a sus superiores, para que procedan contra ellos, y los remuevan, y corrijan, como personas que se oponen á la paz y gobierno público» ${ }^{21}$

Sobre la organización y funcionamiento de estas poblaciones, cabe destacar en primer lugar la atención al cuidado religioso, garantizando la legislación que no faltara asistencia al respecto ${ }^{22}$, así como que el emplazamiento de los poblamientos gozara de los suficientes medios de subsistencia, "Los sitios en que se han de formar Pueblos, y Reduc-

\footnotetext{
${ }^{20}$ Ley I, Libro VI, Título III.

21 Ley III, Título III. Libro VI.

${ }^{22}$ Véase al respecto, Leyes IV, V, VI y VII. Título III. Libro VI.
} 
ciones, tengan comodidad de aguas, tierras y montes, entradas y salidas, y labranzas, y un exido de una legua de largo, donde los Indios puedan tener sus ganados, sin que se revuelvan con otros de Españoles» ${ }^{23}{ }^{24}$. A tal efecto, los emplazamientos debían hacerse en lugares que asegurasen el mantenimiento de la población, tanto de carácter agrícola, ganadero o de riqueza minera, procurando que los poblamientos se lleven a cabo con el menor desplazamiento posible de indios, «que siendo traídos de Pueblos y Provincias muy distantes, reciben daño y perjuicio... Se traigan de los lugares más cercanos, para que estén aviadas, y la mudanza no sea de tierra fría a caliente, ni al contrario... $\gg^{25}$.

Sobre la organización política de estas comunidades, se proclama en las Leyes de indias, que las mismas estén regidas por Alcaldes y Regidores indios, "Ordenamos que en cada Pueblo, y Reducción haya un Alcalde Indio de la misma Reducción; y si pasare de ochenta casas, dos Alcaldes, y dos Regidores, también Indios; y aunque el Pueblo sea muy grande, no haya mas que dos Alcaldes, y cuatro Regidores; y si fuere de menos de ochenta Indios, y llegare á quarenta, no mas de un Alcalde, y un Regidor, los quales han de elegir por año nuevo otros, como se practica en Pueblos de Españoles, é Indios, en presencia de los Curas» ${ }^{26}$; las atribuciones de estas autoridades indígenas eran las comunes a dichas jerarquías municipales en la Corona, «estará el gobierno de los Pueblos á cargo de los dichos Alcaldes y Regidores en cuanto á lo universal» ${ }^{27}$; aunque su jurisdicción sólo se consideraba referente a la población originaria americana, podían detener y poner presos a negros y mestizos, cuya custodia se mantenía hasta la llegada de la autoridad española competente ${ }^{28}$. No obstante, debe desta-

${ }^{23}$ Ley VIII Título III. Libro VI.

${ }^{24}$ Sobre este punto debe destacarse los extensos condicionamientos que se ponían a los lugares donde debían establecerse las ciudades americanas, en las que se radicaría la población europea, motivo por el que sobre una misma ciudad, en algunos casos se producen varias refundaciones; sobre este punto, véase Libros III, IV y V. Recopilación de Leyes de Indias. Así mismo, debe destacarse, que una vez aprobado el lugar donde tendría lugar el asentamiento poblacional indígena, el mismo no podía cambiarse, sin orden del Rey, Virrey o Audiencia, lo que podía considerarse como una garantía para las comunidades indígenas, «Ningún Gobernador, Corregidor, ó Alcalde mayor, ú otra qualquier Justicia, ha de poder alterar, ni mandar mudar los Pueblos, ni Reducciones, que una vez estuvieren hechos, y fundados, sin nuestra expresa, ó del Virey, Presidente, ó Audiencia Real del distrito... y pues estos pedimentos suelen ser las mas veces procurados por intereses particulares, y no de los Indios, siempre se haga relación de esta ley...» Ley XII Título III. Libro VI.

${ }^{25}$ Ley X Título III. Libro VI; véase igualmente Ley XIII, Título I, Libro VI.

${ }^{26}$ Ley XV Título III. Libro VI.

27 Ley XVI Título III. Libro VI.

${ }^{28}$ Ley XVII. Título III. Libro VI. 
carse, que junto a la organización política correspondiente a los pueblos de Indios y la propiamente española, existía la de carácter tradicional de los pueblos originarios, cuyo vértice estaba representado por los Caciques, a este respecto, cabe destacar, que las citadas Leyes de Indias dedican todo el Título VII del Libro VI a la regulación de esta figura, a la que aun conservando dignidad y propiedades, disminuyen en gran medida sus atribuciones de carácter político, que pasan a ser ejercidas por las autoridades indígenas de los Pueblos, salvo lo referente "al repartimento de las mitas de sus Indios» ${ }^{29}$, aunque los tributos que debían recibir los mismos por parte de los Indios no podía tener un carácter abusivo, debiendo abonar salario a sus trabajadores, encargando a Alcaldes Mayores y Corregidores, el control a este respecto ${ }^{30}$, así mismo, se les prohibía la tenencia de escla$\operatorname{vos}^{31}$.

La separación de los Pueblos de españoles y de indios se pone de manifiesto en la prohibición a los primeros de vivir en los correspondientes a los segundos, prohibición que se hace extensiva a las otras etnias (negros, mestizos y mulatos), la argumentación de la Corona para ello es la defensa de las poblaciones originarias americanos de las malas influencias de ciertos sectores de los primeros, «prohibimos y defendemos, que en las Reducciones, y Pueblos de Indios puedan vivir, ó vivan Españoles, Negros, Mulatos, ó Mestizos, porque se ha experimentado, que algunos Españoles, que tratan, traginan viven, y andan entre los Indios, son hombres inquietos, de mal vivir, ladrones, jugadores, viciosos, y gente perdida, y por huir los Indios de ser agraviados, dexan sus Pueblos, y Provincias, y los Negros, Mestizos, y Mulatos, demás de tratarlos mal, se sirven de ellos, enseñan sus malas costumbres, y ociosidad, y también algunos errores, y vicios, que podrán estragar, y pervertir el fruto que deseamos en orden á su salvación, aumento, y quietud; y mandamos, que sean castigados con graves penas, y no consentidos en los Pueblos ${ }^{32}$; y los Vireyes, Presidentes, Gobernadores, y Justicias tengan mucho cuidado de hacerlo executar donde por sus personas pudieren, ó valiéndose de Ministros de toda integridad: y en cuanto á los Mestizos, y Zambaygos, que son hijos de Indias, nacidos entre ellos, $y$ han de heredar sus casas, y haciendas, porque parece cosa dura separarlos de sus padres, se podrá dispensar» ${ }^{33}$.

${ }^{29}$ Ley XV Título III. Libro VI.

${ }^{30}$ Ley VIII y X. Título VII. Libro VI.

31 Ley III. Título II. Libro VI.

32 La prohibición se mantenía, aunque los mismos tuvieran propiedades en las zonas de referencia; Ley XXII. Título III. Libro VI.

33 Ley XXI. Título III. Libro VI. 
A modo de conclusión, de lo anteriormente indicado, se puede concluir, que durante el periodo colonial, aunque se produjo una cierta marginación de la población originaria americana, ésta no estuvo exenta de serios intentos de asimilación e integración por parte de la Corona, debiendo resaltarse la aplicación en muchos aspectos del principio de igualdad de claros orígenes cristianos, al que se accedía en virtud de la aceptación de la Religión del Estado.

Aunque las condiciones de trabajo de los pueblos originarios americanos no estuvieron exentas de una gran dureza, especialmente en las Encomiendas, debe indicarse, que éstas, a diferencia de lo acaecido en otros Imperios de la época, e incluso en momento posterior, estaban sometidas a Derecho, existiendo una amplia legislación al respecto, debiendo destacarse la absoluta prohibición de la esclavitud para los pueblos originarios del continente y la necesidad de que el trabajo fuera remunerado en salario.

La existencia de Cabildos y Pueblos Indios, aunque tutelados por la Corona, supusieron una primera forma de organización y funcionamiento autónomos.

Por último, debe resaltarse, la existencia de una serie de derechos individuales y garantías de los mismos concedida por la Corona, entre los puede destacarse por su temprana formulación los referentes a la familia y la mujer. No obstante, no debe olvidarse el momento histórico y las circunstancias de la aplicación de esta legislación, de tal forma, que como diría siglos más tarde el constituyente gaditano, representante de Puerto Rico, Ramón Power las leyes en el ancho mar se acababan diluyendo.

\section{TRATAMIENTO DEL TEMA EN EL PRIMER CONSTITUCIONALISMO HISPANOAMERICANO}

En este punto analizaremos el tratamiento de los pueblos originarios americanos en los primeros textos constitucionales correspondientes al primer Estado de Derecho en los Estados surgidos tras el proceso de emancipación de la Corona española, a este respecto estableceremos en primer lugar lo proclamado al respecto en el primer constitucionalismo español, textos de Bayona de 1808 y Cádiz de 1812.

\subsection{En el constitucionalismo español}

En el primer texto constitucional español, aunque el mismo no 
pueda ser considerado como una auténtica Constitución, en cuanto no es consecuencia del ejercicio del Poder Constituyente de la Nación española, ni representa un acto de la soberanía española, ya que se trata de una Carta Otorgada por el Emperador Napoleón Bonaparte ${ }^{34}$, sí representa el punto de partida del intento de conformar un primer Estado de Derecho para España y la América Española. No obstante, su nula vigencia en tierras americanas y el corto periodo que lo estuvo en España, impide un pormenorizado análisis de dicho texto. Debe destacarse sin embargo, que en el mismo se hace referencia a los territorios de América y sus habitantes, a los que otorga representación en Cortes, según previene el artículo 54, y aunque no menciona si los que pueden ejercer sufragio activo y pasivo se reserva al estamento criollo o incluye a la totalidad de la población americana libre, en virtud del artículo 93; debe desecharse la idea de representación de la población originaria americana, en cuanto que en el citado artículo se proclama que para ser nombrado diputado éstos «deberán ser propietarios de bienes raíces», lo que en la práctica excluía a este sector de la población, o al menos a la gran mayoría del mismo.

En la Constitución de 1812, primer texto plenamente constitucional, en cuanto proclama la soberanía nacional y fue elaborado por los representantes de la Nación española, incluida la referente a los territorios americanos, debe indicarse, que aunque escasa, sí tuvo vigencia en España y en las tierras americanas; en el mismo, ya en su artículo 1, se proclama que la Nación española es la reunión de todos los españoles de ambos hemisferios, considerando como tales a «Todos los hombres libre nacidos y avecindados en los dominios de las Españas, y los hijos de éstos» ${ }^{35}$, de esta forma se incluye en el concepto de español a los pueblos originarios americanos, ya que como se indicó en epígrafe anterior del presente trabajo, los mismos no podían estar sujetos a esclavitud, expresión que se proclama de forma completamente diáfana en el Capítulo IV «De los ciudadanos españoles», que en su artículo 18 manifiesta, "Son ciudadanos aquellos españoles que por ambas lineas traen su origen de los dominios españoles de ambos hemisferios y están avecindados en cualquier pueblo de los mismos dominios». De esta forma, se otorga la plena ciudadanía a los originarios de América, que como se desarrolla en el amplio Título III pueden ejercer los derechos de sufragio activo y pasivo, lo que no ocurre con los originarios de África, sean esclavos o no, ya que el artí-

34 Véase al respecto, NÚÑEZ RIVERO, Cayetano (1997), «Historia constitucional de España», Ed. Universitas, Madrid, pág. 35 y ss.

35 Artículo 5.Primero. 
culo 22 le niega tal condición de ciudadanos, a no ser que cumplan determinados requisitos, que les haga merecedores de tal derecho.

\subsection{En el primer constitucionalismo americano}

Como se indicó anteriormente, este periodo de caracteriza por el intento de asimilacionismo, lo que implicaba la eliminación de las viejas Leyes de Indias que permitían una cierta conservación de ámbitos autónomos para las comunidades originarias americanas. Se trataba de la incorporación del indígena a las leyes y formas de vida del Estado naciente, eliminando otras de carácter diferenciado por razones de índole cultural y de costumbres ${ }^{36}$.

Como indica Durán Böhme, Juan Carlos ${ }^{37}$; en el constitucionalismo del primer Estado de Derecho hispanoamericano, se impuso el principio de norma escrita y codificada, desarrollando el paradigma positivista tanto en el reconocimiento de las fuentes, como en la aplicación del Derecho, de tal forma, que el único origen legítimo y legalmente reconocido de creación de normas jurídicas era el Estado, así los sistemas jurídicos alternativos que, como los indígenas, habían recibido algún reconocimiento durante el periodo colonial fueron completamente desconocidos.

La conformación del primer Estado de Derecho se lleva a cabo siguiendo el modelo imperante en la época, que es el norteamericano y francés, que tiene en su base los principios de igualdad jurídica de los ciudadanos, así como los derechos y libertades individuales, sin considerar los derechos sociales o colectivos; así mismo, el nuevo sistema, al igual que otros Estados europeos, se asentaba en el concepto de «Estado-Nación», que partía del principio de la homogeneidad cultural de sus ciudadanos.

A este respecto, nos resulta sumamente ilustrativo el artículo 200 de la Constitución venezolana de 1811, que no sólo es el primer texto constitucional latinoamericano, sino también el primero redactado en

\footnotetext{
${ }^{36}$ Valga como ejemplo el artículo 201 de la constitución venezolana de 1811, "Se revocan por consiguiente y quedan sin valor alguno leyes que en el anterior gobierno concedieron ciertos tribunales, protectores y privilegios de menor a dichos naturales, las cuales dirigiéndose al parecer a protegerlos, les han perjudicado sobre manera, según ha acreditado la experiencia».

37 El Estatuto jurídico de los pueblos indígenas en la República de Bolivia: Una aproximación crítica desde el constitucionalismo, Dpto. $\mathrm{D}^{\circ}$ Constitucional, Univ. Complutense, Madrid, 2006.
} 
lengua castellana, con la excepción ya indicada anteriormente del Estatuto de Bayona.

"Como la parte de ciudadanos que hasta hoy se han denominado Indios, no han conseguido el fruto apreciable de algunas leyes que la Monarquía Española dictó a su favor, porque los encargados del gobierno en estos países tenían olvidada su ejecución; y como las basas del sistema de gobierno que en esta Constitución ha adoptado Venezuela, no son otras que la de la justicia y la igualdad, encarga muy particularmente a los Gobiernos provinciales, que así como han de aplicar sus fatigas y cuidados para conseguir la ilustración de todos los habitantes del Estado, proporcionarles escuelas, academias y colegios en donde aprendan todos los que quieran los principios de Religión, de la sana moral, de la política, de las ciencias y artes útiles y necesarias para el sostenimiento y prosperidad de los pueblos, procuren por todos los medios posibles atraer a los referidos ciudadanos naturales a estas casa de ilustración y enseñanza, hacerles comprehender la intima unión que tiene con todos los demás ciudadanos, las consideraciones que como aquellos merecen del Gobierno y los derechos de que gozan por el solo hecho de ser hombres iguales a todos los de su especie, a fin de conseguir por este medio sacarlos del abatimiento y rusticidad en que los ha mantenido el antiguo estado de cosas y que no permanezcan por más tiempo aislados y aun temerosos de tratar a los demás hombres; prohibiendo desde ahora que puedan aplicarse involuntariamente a prestar sus servicios a Tenientes o Curas de sus parroquias, ni a otra persona alguna y permitiéndoles el reparto en propiedad de las tierras que les estaban concedidas y de que están en posesión, para que a proporción entre los padres de familia de cada pueblo, las dividan y dispongan de ellas como verdaderos señores, según los términos y reglamentos que formen los Gobiernos provinciales».

Se trata por tanto de un constitucionalismo, que por una parte eleva al indígena a la categoría de ciudadano, pero a costa de renunciar a su identidad cultural, de la que quedará despojado, mediante su acceso a la enseñanza y la ilustración, de esta forma, como indica Alexander LUZARDO ${ }^{38}$, se impondrá un constitucionalismo integracionista y asimilacionista de clara factura etnocéntrica, presente en la ideología de la ilustración europea y en la Constitución de los Estados Unidos de Norteamérica, que tanto influyeron en los constituyentes hispanoamericanos. Reducir ${ }^{39}$, civilizar, son conceptos que se plasmarán en los textos jurídicos y en el leguaje usual de la clase

38 LUZARDO NAVA, Alexander, «Constituyente y derechos indígenas», Opinión, Caracas 12 de marzo de 1999.

39 El término reducir se utiliza en varios textos constitucionales hispanoamericanos, a modo de ejemplo podemos citar que hasta la Constitución de 1925 de Venezuela se proclamaba que no se computarían en la base de la población los indígenas «no reducidos». 
política latinoamericana. De esta manera, la integración se quería llevar a cabo en virtud de un proceso de "aculturación», ya que se efectuaba según los patrones culturales y jurídicos de la sociedad dominante en el país, de tal forma, que el reconocimiento de la nacionalidad indígena a los miembros de las comunidades originarias, debía considerarse de carácter individual y no implicaba incorporación al Estado de la concepción de sociedad que estas «Naciones» pudieran tener, tanto en sus acervos culturales como en la forma de organización institucional en su comunidad políticamente organizada.

De esta forma, bajo la concepción de pueblo originario americano igual a ciudadano, en los textos constitucionales hispanoamericanos se omiten referencias específicas a las comunidades originarias americanas, como elemento diferenciado del resto de la nación ${ }^{40}$.

Por otra parte, el proceso de integración de las comunidades originarias, se vería seriamente alterada, convirtiéndose en marginación, pues aunque se proclamaba la inclusión en el concepto Nación a dichas comunidades, al mismo tiempo, se promulgaban aspectos altamente restrictivos al ejercicio de la soberanía nacional mediante el sufragio censitario y capacitario, que se prolongaría hasta bien entrado el siglo XX y que afectaban de forma mayoritaria a los miembros de estas comunidades, que pueden situarse en el estadio de pobreza, conformando de hecho una ciudadanía de carácter restringida.

\section{EL ESTADO PLURINACIONAL LATINOAMERICANO EN LA ACTUALIDAD}

En el nuevo constitucionalismo latinoamericano vigente en determinados países que cuentan con una amplia población de comunidades originarias americanas (Bolivia, Ecuador) se proclama la refundación del Estado, debiendo entenderse esta refundación no sólo como un profundo cambio del Estado llevado a cabo mediante una amplia reforma de las estructuras e instituciones del mismo, sino

${ }^{40}$ Valga como ejemplo, que en la propia Acta de Independencia de Bolivia de seis de agoto de 1825, sólo hay una referencia y de carácter paternalista al elemento indígena, que nos lo presenta como algo aislado al proceso que estaba acaeciendo en el país y ajeno de todo protagonismo en el mismo «venid, en fin, y si cuando contempléis a nuestros hermanos indígenas, hijos del grande Manco Kapac, no se cubren vuestros ojos de torrentes de lágrimas, viendo en ellos hombres los más desgraciados, esclavos tan humillados, seres sacrificados a tantas clases de tormentos, ultrajes y penurias, diréis respecto de ellos parecerían los ilotas, ciudadanos de Esparta(...)». 
que tiene un carácter de mayor profundidad, en cuanto que lo que «refunda» no se limita a la filosofía inspiradora del Estado y al aparato institucional del mismo, sino que incide en la propia refundación de uno de los elementos imprescindibles del Estado, como es la «Nación ${ }^{41}$, Incorporando plenamente a los pueblos y naciones indígenas al concepto de nación, con lo que transforma el mismo concepto.

En este proceso de reconocimiento constitucional a las comunidades originarias americanas, a las que la Constitución boliviana define como "Es nación y pueblo indígena originario campesino toda la colectividad humana que comparta identidad cultural, idioma, tradición histórica, instituciones, territorialidad y cosmovisión, cuya existencia es anterior a la invasión colonial española ${ }^{42}$, se incide especialmente en el principio autonómico y el derecho a la libre determinación de estos pueblos.

A este respecto, debe entenderse que el concepto de Autonomía que se maneja en los textos de referencia es de carácter política y no sólo administrativa, que se refuerza con el de libre determinación de las Comunidades originarias, de tal forma, que en virtud de los Tratados internacionales firmados por estos Estados ${ }^{43}$, que los han incorporado a su derecho interno e incluso incluido en el denominado Bloque de constitucionalidad.

A este respecto, nos referimos a lo proclamado al respecto en el texto boliviano, en los ámbitos político y económico, «En el marco de la unidad del Estado y de acuerdo con esta Constitución las naciones y pueblos indígena originario campesinos gozan de los siguientes derechos(...) A ser consultados mediante procedimientos apropiados, y en particular a través de sus instituciones, cada vez que se prevean medidas legislativas o administrativas susceptibles de afectarles. En este marco, se respetará y garantizará el derecho a la consulta previa obligatoria, realizada por el Estado, de buena fe y concertada, respecto a la explotación de los recursos naturales no renovables en el territorio que habitan ${ }^{44}$, que reproduce casi íntegramente el artículo $6^{\circ}$ a) del Convenio 169 de la OIT, y varios preceptos de la declaración de las Naciones Unidas sobre los derechos de los pueblos indígenas ${ }^{45}$. En la

41 Véase al respecto, NÚÑEZ RIVERO, Cayetano; «Derecho Constitucional Comparado y Derecho Político iberoamericano»; ob. ant. cit., pág. 426.

42 Artículo 30. I. Constitución boliviana.

43 Convenio 169 de la OIT y la Declaración de Naciones Unidas sobre Derechos de los Pueblos indígenas.

${ }_{44}$ Artículo 30.II. 15.

45 Artículos 3, 5, 18, 19, 20, 26 y 27. 
misma línea, referente a la explotación de la riqueza nacional, se mantiene el principio de consulta a la población afectada en el territorio objeto de explotación, así, aún cuando el Estado proclama la propiedad de la misma y su administración ${ }^{46}$, reitera la necesidad de consulta a la población afectada ${ }^{47}$.

Sobre este punto, lo que queda por delimitar es si la consulta que debe realizar el Estado, que entendemos es obligatoria, si así lo solicita la comunidad afectada, tiene un mero carácter consultivo, o por el contrario es vinculante. A este respecto, si nos atenemos a lo dispuesto en los tratados y convenios internacionales, que como se indicó anteriormente forman parte del bloque de constitucionalidad y son norma interna, se imposibilitaría toda acción de gobierno contraria a las decisiones de la comunidad afectada, lo que en determinados casos puede provocar un grave problema a los intereses generales del Estado.

46 Artículos 311.2 y 349.I.C.B.

47 Artículo 352. C.B. 